Cornell Law Library

Scholarship@Cornell Law: A Digital Repository

Cornell Law Faculty Publications

Faculty Scholarship

$12-1-2011$

\title{
To Dollars from Sense: Qualitative to Quantitative Translation in Jury Damage Awards
}

Valerie P. Hans

Cornell Law School, valerie.hans@cornell.edu

Valerie F. Reyna

Cornell University

Follow this and additional works at: http://scholarship.law.cornell.edu/facpub

Part of the Civil Law Commons, $\underline{\text { Courts Commons, and the Torts Commons }}$

\section{Recommended Citation}

Hans, Valerie P. and Reyna, Valerie F., "To Dollars from Sense: Qualitative to Quantitative Translation in Jury Damage Awards" (2011). Cornell Law Faculty Publications. Paper 638.

http://scholarship.law.cornell.edu/facpub/638

This Article is brought to you for free and open access by the Faculty Scholarship at Scholarship@Cornell Law: A Digital Repository. It has been accepted for inclusion in Cornell Law Faculty Publications by an authorized administrator of Scholarship@Cornell Law: A Digital Repository. For more information, please contact jmp8@cornell.edu. 


\title{
To Dollars from Sense: Qualitative to Quantitative Translation in Jury Damage Awards
}

\author{
Valerie P. Hans and Valerie F. Reyna*
}

\begin{abstract}
This article offers a new multistage account of jury damage award decision making. Drawing on psychological and economic research on judgment, decision making, and numeracy, the model posits that jurors first make a categorical gist judgment that money damages are warranted, and then make an ordinal gist judgment ranking the damages deserved as low, medium, or high. They then construct numbers that fit the gist of the appropriate magnitude. The article employs data from jury decision-making research to explore the plausibility of the model.
\end{abstract}

\section{INTRODUCTION}

This article proposes a new model of perhaps the most controversial aspect of the civil jury's decision making, its determination of compensatory and punitive damage awards. As Edie Greene and Brian Bornstein write in Determining Damages: "Our understanding of how people translate an individual's misfortune into a monetary value is rudimentary and elusive.... Understanding the psychological processes underlying these complex decisions is of significant import." The article builds on theory and research by psychologists, economists, and legal scholars to create a comprehensive account of jury damage award decision making. A major goal of this model-building is to identify strengths and limitations of lay citizen decision making about dollar awards. The article also explores the implications of the model for reforms to the jury damage award decision process.

\footnotetext{
*Address correspondence to Valerie P. Hans, Professor of Law, Cornell University Law School, Myron Taylor Hall, Ithaca, NY 14853; email: vh42@cornell.edu. Reyna is Professor of Human Development and Psychology, Cornell University. Both authors are Fellows of the Cornell University Institute for the Social Sciences, 2009-2012.

We thank the ISS Judgment, Decision Making and Social Behavior team members for their collegial and insightful comments on our work during the fellowship period. We also thank Edie Greene and Jeffrey Rachlinski for their thoughtful comments on a previous draft of this article, and Francoise Vermeylan for invaluable statistical advice.
}

${ }^{1}$ Edie Greene \& Brian H. Bornstein, Determining Damages: The Psychology of Jury Awards 173 (2003). 


\section{Background: Jury Damage Awards as a Lightening ROD FOR CRITICISM}

The jury as an institution is highly regarded by the public. However, Americans are more enamored of the criminal jury than the civil jury. ${ }^{2}$ Many perceive civil jurors as overly generous to plaintiffs, hostile to large businesses and corporations, and influenced by biases and prejudices. ${ }^{3}$ Their awards are seen as erratic and unprincipled. ${ }^{4}$ Large jury damage awards receive disproportionate coverage in the media. ${ }^{5}$ Lawyers and their clients regularly express dismay over what they perceive as the rampant unpredictability of jury awards, which makes it difficult for them to assess in advance whether to proceed with a case or to settle to avoid a more damaging loss from a substantial jury verdict. ${ }^{6}$ Responding to interest group demands to impose limits on damage awards, state legislatures across the country have passed a variety of reforms over the last few decades, including dollar limits or caps on noneconomic damage awards, total damage awards, and punitive damage awards. ${ }^{7}$ New limitations have also emerged in the course of litigation over punitive damages. In a number of decisions over the last two decades, the U.S. Supreme Court has examined the constitutional dimensions of punitive damages; many commentators believe that concern about irrational jury punitive damage awards motivated the Court. ${ }^{8}$

In our view, these legislative and doctrinal changes have not usually been informed by a clear and complete understanding of how juries decide on money damages. It is not surprising, then, that some reforms have had unexpected effects. For instance, introducing

${ }^{2}$ Valerie P. Hans, Attitudes Toward the Civil Jury: A Crisis of Confidence? In Verdict: Assessing the Civil Jury System 248 (Robert E. Litan ed., 1993).

${ }^{3}$ Id. at 257-61; see also Valerie P. Hans, Business on Trial: The Civil Jury and Corporate Responsibility 58-67 (2000).

${ }^{4}$ Hans, Business on Trial, supra note 3 , at 58-67.

${ }^{5}$ Robert J. MacCoun, Media Reporting of Jury Verdicts: Is the Tail (of the Distribution) Wagging the Dog? 55 DePaul L. Rev. 539 (2006).

${ }^{6}$ Valerie P. Hans \& Theodore Eisenberg, The Predictability of Juries, 60 DePaul L. Rev. 375 (2011); Jane GoodmanDelahunty, Pär Anders Granhag, Maria Hartwig \& Elizabeth F. Loftus, Insightful or Wishful: Lawyers' Ability to Predict Case Outcomes, 16 Psychol. Pub. Pol'y \& L. 133 (2010); Jonas Jacobson, Jasmine Dobbs-Marsh, Varda Liberman \& Julia Minson, Predicting Civil Jury Verdicts: How Attorneys Use (and Misuse) a Second Opinion, J. Empirical Legal Stud. (this issue).

${ }^{7}$ See Ronen Avraham, Database of State Tort Law Reforms (DSTLR 4th) (Sept. 2011) <http://ssrn.com/abstract; 902711>. Similar reform efforts undertaken at the federal level have been stymied thus far. See Michael P. Allen, A Survey and Some Commentary on Federal "Tort Reform," 39 Akron L. Rev. (2006); Robert S. Peck, In Defense of Fundamental Principles: The Unconstitutionality of Tort Reform, 31 Seton Hall L. Rev. 672 (2000-2001); Effects of Tort Reform: Evidence from the States (Congressional Budget Office, June 2004) <http://www.cbo.gov/ doc.cfm? index $=5549$ \&type $=0 \&$ sequence $=2>$.

${ }^{8}$ Exxon Shipping Co. v. Baker, 554 U.S. 471 (2008). See also Catherine M. Sharkey, The Exxon Valdez Litigation Marathon: A Window on Punitive Damages, 7 U. St. Thomas L.J. 25 (2009) (summarizing Exxon Valdez litigation). 
caps on damage awards has had the paradoxical effect of increasing average damage awards in some jurisdictions. ${ }^{9}$

\section{Research on Jury Damage Awards}

Responding to the public and legal attention devoted to high-profile jury awards, legal scholars, psychologists, and economists have taken up the subject of jury damage award decision making. Some of that work indicates that jurors face great difficulty in fairly and equitably deciding on money damages, whereas other research offers a more optimistic picture. ${ }^{10}$

Jurors report being deeply challenged by the task of arriving at damage awards. ${ }^{11}$ Valerie Hans interviewed 269 civil jurors who had decided cases in which at least one of the litigants was a corporation or a business. The juror interviews included a host of questions about how the jury went about deciding on compensatory damages and, if applicable, punitive damages. The interviews confirmed that jurors were often at sea as they began to discuss what would constitute an appropriate award in the case. By their own account, many jurors entered the jury deliberation room with no specific figure in mind. Numbers emerged only during the course of deliberation, as they discussed the case particulars and the plaintiff's injuries with the other jurors. ${ }^{12}$ Even then, jurors reported that it was challenging to come up with dollar amounts that corresponded to the injury. As one juror, who decided a medical malpractice case in which the plaintiff had half of one lung mistakenly removed, reflected on the process:

Out of anything I can say I hated, that was the part I hate the most. Because I just don't think it was fair that we had to put a dollar amount on this . . . we weren't given a minimum . . . we weren't given a maximum. We were told to go into the room. Lock yourselves in there and don't come out until you have a dollar amount. And I thought that was very unfair, especially when we were just regular everyday citizens. And we have no idea what is ordinary and customary in a case like

\footnotetext{
${ }^{9}$ Ronen Avraham \& Álvaro Bustos, The Unexpected Effects of Caps on Noneconomic Damages, 30 Int'l Rev. L. \& Econ. 291 (2010); Catherine Sharkey, Crossing the Punitive-Compensatory Divide, in Civil Juries and Civil Justice: Psychological and Legal Perspectives 79 (Brian H. Bornstein, Richard L. Wiener, Robert Schopp \& Steven Willborn eds., 2008).

${ }^{10}$ For summaries of the research on jury damage awards, see Greene \& Bornstein, Determining Damages, supra note 1; Valerie P. Hans \& Stephanie Albertson, Empirical Research and Civil Jury Reform, 78 Notre Dame L. Rev. 1497 (2003); Jennifer K. Robbennolt, Punitive Damages Decision Making: The Decisions of Citizens and Trial Court Judges, 26 Law \& Hum. Behav. 315 (2002). When it comes to experiencing difficulty in valuing injuries, juries have company at the highest levels of government. See, for example, Binyamin Appelbaum, A Life's Value? It May Depend on the Agency, NY Times, Feb. 17, 2011, at A1, A3 (finding that the dollar value of a human life varies for different government agencies).
}

${ }^{11}$ Hans, Business on Trial, supra note 3 .

${ }^{12}$ Nicole L. Mott, Valerie P. Hans \& Lindsay Simpson, What's Half a Lung Worth? Civil Jurors' Accounts of Their Award Decision Making, 24 Law \& Hum. Behav. 401 (2000). 
this ... And I think if we could have had some type of guide, monetary guideline, as to okay this is the minimum, this is the maximum, and then you decide. But I mean it was like, if we said he's awarded a dollar was this satisfactory? We didn't know. ${ }^{13}$

A collaborative research group of economists, psychologists, and law professors undertook one high-profile project that examined the process of punitive damage award decision making by juries. ${ }^{14}$ The researchers began by noting that dollar awards are likely to be highly variable because they are assessed on an unbounded scale. The minimum is set at zero, but there is, at least theoretically, no maximum amount. ${ }^{15}$ This contrasts with bounded scales, where both the minimum and maximum levels are established in advance. The research group adopted a mock jury approach to examine how juries reach punitive damages decisions. They concluded on the basis of their experimental research that although mock jurors showed substantial consensus about the relative merits of the different cases, their dollar awards varied dramatically. ${ }^{16}$ One cause of the variation, the authors say, is that individuals translated their sense of outrage onto the unbounded dollar scale differently, so that people with similar judgments about the wrongfulness of the defendant's behavior chose different dollar values. In their study, the group decision-making process, rather than producing an average of individuals' different award preferences, resulted in more extreme awards in the direction of the group's majority. ${ }^{17}$

Outside the jury decision-making context, research on citizen competence with numbers gives rise to concern about the ability of laypersons to decide damage awards rationally. Work on the public's mathematical proficiency, or numeracy, routinely finds that people have trouble with numbers. ${ }^{18}$ An estimated 93 million Americans are not proficient with numbers, and low numeracy (i.e., the inability to understand and use

\footnotetext{
${ }^{13}$ Mott et al., supra note 12 , at 409 .

${ }^{14}$ Cass R. Sunstein, Reid Hastie, John W. Payne, David A. Schkade \& W. Kip Viscusi, Punitive Damages: How Juries Decide (2002).

${ }^{15}$ Id. at 41 .

${ }^{16}$ Id. at 43-61 (describing study results).

${ }^{17}$ Id. See also Cass R. Sunstein, Daniel Kahneman, David Schkade \& Ilana Ritov, Predictably Incoherent Judgments, 54 Stan. L. Rev. 1153 (2002); Neil Vidmar, Experimental Simulations and Tort Reform: Avoidance, Error and Overreaching in Sunstein et al.'s Punitive Damages, 53 Emory L.J. 1359 (2004) (criticizing the research program on methodological grounds); Richard L. Weiner, Point and Counterpoint: A Discussion of Jury Research in the Civil Arena, 23 Law \& Hum. Behav. 703 (1999) (introducing a special section of the journal devoted to scholarly assessments of the punitive damages research project as well as author responses).
}

${ }^{18}$ Valerie F. Reyna \& Charles J. Brainerd, Numeracy, Ratio Bias, and Denominator Neglect in Judgments of Risk and Probability, 18 Learning \& Individual Differences 89 (2008) [hereinafter Reyna \& Brainerd, Numeracy, Ratio Bias, and Denominator Neglect]; Valerie F. Reyna \& Charles J. Brainerd, The Importance of Mathematics in Health and Human Judgment: Numeracy, Risk Communication, and Medical Decision Making, 17 Learning \& Individual Differences 147 (2007) [hereinafter Reyna \& Brainerd, Importance of Mathematics]. 
numbers) is even more prevalent among subgroups such as the poor and the old. ${ }^{19}$ People tend to overestimate frequencies compared to probabilities. They pay little attention to base rates, underestimate disjunctive and overestimate conjunctive probabilities, neglect denominators in ratios, and make other errors. ${ }^{20}$

Economists and psychologists who study how people make financial decisions likewise find many domains in which people's numerical judgments fall short of ideal. ${ }^{21}$ People can go wrong in a multitude of ways when they think about money matters. ${ }^{22}$ People are affected by phenomena such as mental accounting, loss aversion, endowment effects, bigness bias, overconfidence, and anchoring. These and other psychological heuristics, which can be useful shortcuts in many types of decision making, can lead to suboptimal financial choices. ${ }^{23}$ Economists identify other troubles people have with numbers. To take one example, "left digit bias" studies find that people pay much more attention to the left as opposed to the right digits of multidigit numbers, and can be misled by pricing that takes advantage of this tendency. ${ }^{24}$ Consumers underestimate the magnitude of precise prices compared to round number prices of similar magnitude. ${ }^{25}$

In sum, basic work in psychology and economics indicates that members of the public, and even experts, often flounder when they are required to make numerical judgments. The problems can be even more acute when it comes to making judgments

\footnotetext{
${ }^{19}$ Valerie F. Reyna, Wendy L. Nelson, Paul K. Han \& Nathan F. Dieckmann, How Numeracy Influences Risk Comprehension and Medical Decision Making, 135 Psychol. Bull. 943 (2009) [hereinafter Reyna et al., How Numeracy Influences Risk Comprehension].
}

${ }^{20}$ Id.; Reyna \& Brainerd, Numeracy, Ratio Bias, and Denominator Neglect, supra note 18.

${ }^{21}$ Nicola Lacetera, Devin G. Pope \& Justin R. Sydnor, Heuristic Thinking and Limited Attention in the Car Market (Sept. 24, 2010) <http://ssrn.com/abstract=1682191>.

${ }^{22}$ Gary Belsky \& Thomas Gilovich, Why Smart People Make Big Money Mistakes . . . and How to Correct Them (2009) (describing heuristics that lead to money mistakes). See also Annamaria Lusardi \& Olivia S. Mitchell, How Much Do People Know About Economics and Finance? Michigan Retirement Research Center, Institute for Social Research, Univ. of Michigan, Policy Brief (2008) <http://www.dartmouth.edu alusardi/Papers/Lusardi-Mitchell08.pdf> (finding low levels of financial literacy); Annamaria Lusardi \& Olivia S. Mitchell, Planning and Financial Literacy: How Do Women Fare? 98 Am. Econ. Rev.: Papers \& Proc. 413 (2008) (finding that financial illiteracy is common among women).

${ }^{23}$ Belsky \& Gilovich, supra note 22.

${ }^{24}$ See Kaushik Basu, Consumer Cognition and Pricing in the Nines in Oligopolistic Markets, 15 J. Econ. \& Mgmt. Strategy 125 (2006) (discussing the common practice of pricing in the nines). Basu discusses potential explanations for the prevalence of pricing in the nines based on consumer behavior, such as consumer irrationality (id. at 127), association with discounted goods (id. at 126), and the greater availability and accessibility of round numbers (id. at 126). He concludes that consumers "do not do this reflexively or out of irrationality, but only when they expect the time cost of acquiring full cognizance of the exact price to exceed the expected loss caused by the slightly erroneous amounts that are likely to be purchased or the slightly higher price that may be paid by virtue of ignoring the information concerning the last digits of prices." Id. at 125. See also Manoj Thomas \& Vicki Morwitz, Penny Wise and Pound Foolish: The Left-Digit Effect in Price Cognition, 32 J. Consumer Res. 54 (2005).

${ }^{25}$ Manoj Thomas, Daniel H. Simon \& Vrinda Kadiyali, The Price Precision Effect: Evidence from Laboratory and Market Data, 29 Marketing Sci. 175 (2010) [hereinafter Thomas, Simon \& Kadiyali, The Price Precision Effect]. 
about money. ${ }^{26}$ The prevalence of low numeracy among members of the public implies that some jurors may not have a clear sense of the magnitude of awards, especially very large awards, and may find the multistep operations used to calculate them daunting. Some damage award determinations are particularly difficult because they include mathematical functions such as compounding, exponential growth, and calculation of present value, phenomena that jurors find hard to understand and apply. ${ }^{27}$ The juror interviews and mock jury experiments suggest that civil jurors find it challenging when they embark, with little guidance, on the task of deciding on money damages for injured plaintiffs. The unbounded scale for dollar damages exacerbates the challenge. All this paints a gloomy picture of the ability of juries to arrive at reasonable damage award decisions.

In contrast to this bleak conclusion, statistical and other analyses of actual jury damage awards offer a more reassuring assessment. ${ }^{28}$ Analyses of civil cases and damage awards routinely find that more serious injuries, measured in a number of different ways, typically produce greater jury damage awards that reflect their relative severity. For example, studies of the closed claims of insurance companies have shown that the magnitude of awards is positively associated with the severity of the injury, such that more serious injuries result in larger awards. Analysis of the actual punitive damage awards reached by juries (and judges) shows that they are awarded infrequently, and occur primarily in intentional tort and fraud cases. On average, punitive damages awards tend to be modest and proportionate to compensatory damages. ${ }^{29}$

Other research using mock scenarios finds that when laypersons, judges, and lawyers review the same case descriptions, the different groups overlap substantially in how they rate injury severity and assess appropriate damage amounts. ${ }^{30}$ As Eisenberg and his colleagues report, despite the fact that there is "convincing empirical evidence that people lack the basic cognitive skills necessary to translate qualitative moral judgments into quantitative numerical scales. ... the research on quantitative judgments demonstrates substantial consistency in judgments.... In civil lawsuits, the worst-behaved defendants who caused the most harm are the most likely to lose and pay the most damages." 31

\footnotetext{
${ }^{26}$ Reyna \& Brainerd, The Importance of Mathematics, supra note 18.
}

${ }^{27}$ Jane Goodman, Edie Greene \& Elizabeth F. Loftus, Runaway Verdicts or Reasoned Determinations: Mock Juror Strategies in Awarding Damages, 29 Jurimetrics J. 285 (1989).

\footnotetext{
${ }^{28}$ See Neil Vidmar \& Valerie P. Hans, American Juries 267-338 (2007). See also Theodore Eisenberg, Jeffrey J. Rachlinski \& Martin T. Wells, Reconciling Experimental Incoherence with Real-World Coherence in Punitive Awards, 54 Stan. L. Rev. 1239, 1241 (2001-2002) [hereinafter Eisenberg et al., Real-World Coherence].
}
${ }^{29}$ Theodore Eisenberg, Valerie P. Hans \& Martin T. Wells, The Relation Between Punitive and Compensatory Awards: Combining Extreme Data with the Mass of Awards, in Civil Juries and Civil Justice: Psychological and Legal Perspec- tives 105 (Brian H. Bornstein, Richard L. Wiener, Robert Schopp \& Steven Willborn eds., 2008).

\footnotetext{
${ }^{30}$ Roselle L. Wissler, Allen J. Hart \& Michael J. Saks, Decisionmaking About General Damages: A Comparison of Jurors, Judges, and Lawyers, 98 Mich. L. Rev. 751 (1999).
}

${ }^{31}$ Eisenberg et al., Real-World Coherence, supra note 28, at 1240, 1241. 
Yet even the statistical analyses show that there is a good deal of variability and unpredictability in both compensatory and punitive damage awards. The models comparing jurors, judges, and lawyers were better able to account for injury severity ratings than they were for dollar award recommendations. ${ }^{32}$ Michael Saks and his colleagues report that even though more serious injuries produce higher dollar awards, there remains substantial variation across individuals in the dollar amounts they give to injuries of similar severity. ${ }^{33}$

\section{A Theoretical Model of Juror Damage Award DECISION MAKING}

We combine theoretical ideas and research findings from psychologists, economists, and legal scholars, and use them to construct a model of juror damage award decision making. The endeavor will, we hope, be useful theoretically and also practically. Our aim is to better understand the process by which jurors move from the qualitative to the quantitative, from sense to dollars. It may also point us in the direction of potential reforms to improve the jury system.

We propose a model that draws to a significant degree on the work done on human information processing and judgment and decision making in general, and fuzzy-trace theory in particular. Fuzzy-trace theory is a theory of memory and cognition that draws on what researchers have learned about judgment and decision processes. Numerous experiments have tested and confirmed the central claims of fuzzy-trace theory in other decisionmaking domains. ${ }^{34}$ Here, for the first time, we apply its insights to damage award decision making.

A key assumption of fuzzy-trace theory is that people encode two parallel types of mental representations (or memory traces) of information. One is a verbatim representation, and the other is a gist representation. Verbatim representations are literal, veridical, and detailed. In contrast, gist representations are centered around the meaning that a person derives from the information. ${ }^{35}$ Verbatim representations preserve the exact surface form of information, such as exact wording and precise numbers, compared to the bottom-

\footnotetext{
${ }^{32}$ Wissler et al., supra note 30 .

${ }^{33}$ Michael J. Saks, Lisa A. Hollinger, Roselle L. Wissler, David Lee Evans \& Allen J. Hart, Reducing Variability in Civil Jury Awards, 21 Law \& Hum. Behav. 243 (1997).

${ }^{34}$ Valerie F. Reyna \& Charles J. Brainerd, Fuzzy-Trace Theory: An Interim Synthesis, 7 Learning \& Individual Differences 1 (1995) [hereinafter Reyna \& Brainerd, Interim Synthesis].

${ }^{35}$ Gist representations are said to be "fuzzy," reflecting the fact that they are not as precise as verbatim representations. Mental representations of information vary along a verbatim-to-gist continuum. Verbatim memory traces preserve veridical details at the precise end of the continuum, whereas gist representations preserve the meanings that have been extracted at the fuzzy end. Valerie F. Reyna \& Wanda Casillas, Development and Dual Processes in Moral Reasoning: A Fuzzy-Trace Theory Approach, in 50 Moral Judgment and Decision Making: The Psychology of Learning and Motivation 207, 208 (D.M. Bartels et al. eds., 2009) (describing fuzzy-trace theory and its application to moral reasoning).
} 
line meaning captured in gist representations. Research has shown that people extract multiple gist representations of the same information, and that verbatim and gist representations are encoded, retrieved, and stored separately and independently. ${ }^{36}$ Reyna and Brainerd have generalized the concepts of gist and verbatim representations beyond verbal information to encompass numbers, graphs, pictures, and other meaningful stimuli. ${ }^{37}$

Gist and verbatim mental representations are associated with different kinds of thinking, and people engage in both forms of thinking at different times. When they make judgments, however, gist tends to be more significant, more important, and more dominant. ${ }^{38}$ So, for example, when presented with a probability describing the likelihood of a future event, an individual may encode the exact probability given, but the underlying meaning of the probability (e.g., coded for gist as low or high risk) is more likely to govern their risk-related behavior.

Gist usually trumps verbatim representations in judgment and decision making, and is used as a default whenever the task allows. However, specific task demands, such as asking for exact numerical judgments, require mental representations that are more precise, and may push people toward the verbatim end of the continuum. Thus, the extent to which verbatim versus gist approaches will emerge as dominant depends in part on the demands of the task, as well as on other features and cues in the context. Task demands force people to make finer distinctions, moving from categorical or all-or-none distinctions (e.g., some money vs. nothing) to ordinal ones (e.g., low vs. high amounts of money) and, if necessary, to numerical estimates (e.g., exact dollar estimates). However, people prefer to operate on fuzzier categorical or ordinal representations of quantity, and have difficulty assigning exact numerical values, especially to unfamiliar entities. For example, classic work on contingent valuation has demonstrated wide swings in estimated willingness to pay to save an endangered species from extinction or to avoid living next to a nuclear power plant. ${ }^{39}$ Fuzzy-trace theory explains this variability in numerical estimates by assuming that values are not fully spelled out in long-term memory and are instantiated depending on the context. People are likely to know whether they highly value saving an endangered species, but they must construct an exact dollar amount to attach to that ordinal judgment of value.

Moreover, according to fuzzy-trace theory, numbers do not have meanings in themselves, even to the highly numerate. The gist or meaning of a number depends on both content and context; it is inherently relative. To illustrate the effect of content, note that a probability of 0.15 of imminent rain is low whereas the same 0.15 probability of an imminent heart attack is high. The effect of context has been demonstrated by showing, for

\footnotetext{
${ }^{36}$ Reyna \& Brainerd, Interim Synthesis, supra note 34.

${ }^{37}$ Id.

${ }^{38}$ The dominance of gist thinking is referred to as a "fuzzy processing preference." Valerie F. Reyna, A Theory of Medical Decision Making and Health: Fuzzy-Trace Theory, 28 Med. Decision Making 850 (2008).

${ }^{39}$ For a discussion of contingent valuation and other phenomena in legal contexts, see Peter H. Huang, Moody Investing and the Supreme Court: Rethinking the Materiality of Information and the Reasonableness of Investors, 13 S. Ct. Econ. Rev. 99 (2005).
} 
example, that a risk of 12 percent is perceived as low relative to 20 percent, but the same 12 percent is perceived as high relative to 4 percent. ${ }^{40}$

Numbers that differentiate categories are interpretable because the differences they span are qualitative rather than quantitative. Thus, a difference between a 1 percent chance of cancer and a 0 percent chance is meaningful in an all-or-none fashion, as are differences such as above and below 50 percent or between 95 percent and 100 percent. One would pay a great deal to reduce cancer risk from 1 percent to 0 percent because these differ categorically. When numbers cross category boundaries, as in these examples, when the number reveals that an event becomes possible rather than impossible, or becomes certain rather than uncertain, those differences are interpretable because their qualitative gist is apparent. Specific numbers can also take on meaning because of content (e.g., a year's earnings of a company) or context (e.g., lifetime earnings of an individual from a poor vs. an affluent community).

An important aspect of fuzzy-trace theory, which stands in contrast to many other dual-process theories, is that gist judgments are not presumed to constitute an intellectually inferior and more primitive form of thinking. Dual-process theories generally contrast "Type 1" or faster and intuitive thinking and "Type 2" or rational and deliberative thinking. Often, the rational, deliberative form of thinking is considered to be superior ${ }^{41}$ However, in many ways gist thinking is quite sophisticated. Adults are more likely to engage in gist thinking compared to children; and in expertise-relevant domains, experts have been found to engage in gist thinking more than nonexperts. ${ }^{42}$ Interestingly, one study found that expert cardiologists employed fewer dimensions of information to make admissions decisions for patients with chest pain, compared to generalists or students, but were nonetheless more accurate according to clinical guidelines. ${ }^{43}$

Standard dual-process theorists have argued that better numeracy should improve decision making, which is in stark contrast to fuzzy-trace theorists, who maintain the distinction between rote computation (how numeracy is typically measured) and meaningful interpretation of numbers. Fuzzy-trace theorists envision that some highly numerate people fit the old maxim, "knowing the price of everything and the value of nothing." One might interpret this as a dual-process distinction between objectivity (price) and sentiment (value). However, when ordinary people use the expression about the price of everything

\footnotetext{
${ }^{40}$ For the content example, see Valerie F. Reyna \& Farrell J. Lloyd, Physician Decision-Making and Cardiac Risk: Effects of Knowledge, Risk Perception, Risk Tolerance, and Fuzzy Processing, 12 J. Experimental Psychol.: Applied 179 (2006). For the context example, see P.D. Windschitl, R. Martin \& A.R. Flugstad, Context and the Interpretation of Likelihood Information: The Role of Intergroup Comparisons on Perceived Vulnerability. 82 J. Personality \& Soc. Psychol. 742 (2002).
}

${ }^{41}$ Jonathan St. B.T. Evans, Dual-Processing Accounts of Reasoning, Judgment, and Social Cognition, 59 Ann. Rev. Psychol. 255 (2008). See also Gideon Keren \& Yaacov Schul, Two is Not Always Better Than One: A Critical Evaluation of Two-System Theories, 4 Persp. Psychol. Sci. 533-50 (2009).

${ }^{42}$ Reyna \& Lloyd, supra note 40.

${ }^{43}$ Id. 
Figure 1: A model of jury damage award decision making.

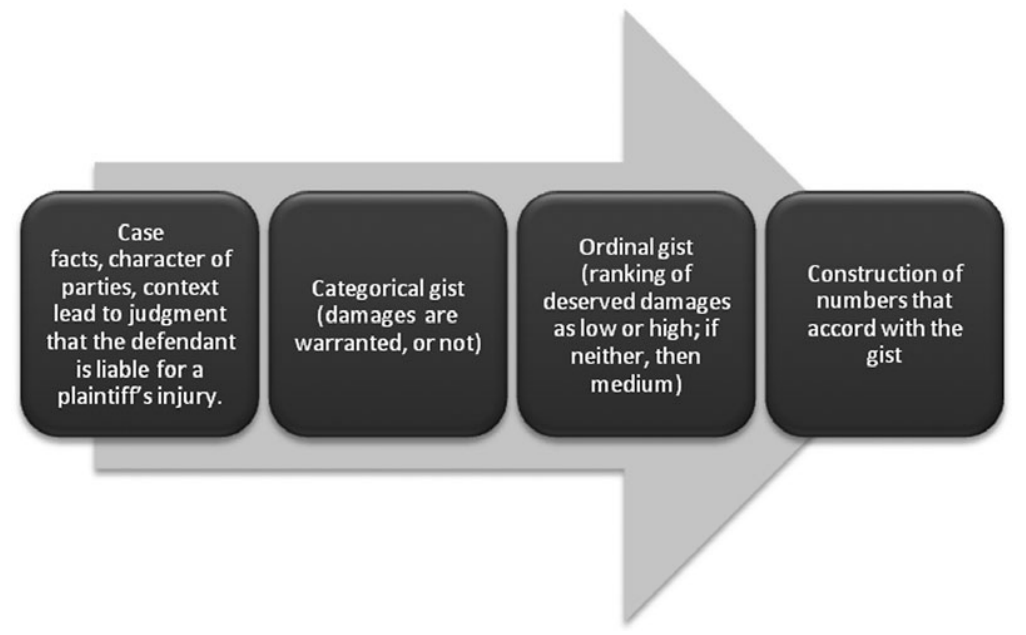

yet the value of nothing, we believe they mean to suggest that a person fixated on verbatim prices has missed the deeper point. Indeed, research has generated paradoxical findings that people higher in numeracy are more likely to rate numerically inferior monetary gambles as more attractive than superior gambles (ones offering a lower potential for losses). ${ }^{44}$ These and other insights have shaped the development of our multistage account.

Figure 1 displays our model of juror damage award decision making. At the start of the trial and throughout the course of the trial, we expect jurors to engage in mainly gist-based reasoning about the plaintiff's injury and the defendant's culpability. The case facts, the character of the parties, the context and nature of the case, individual attitudes, views, and world knowledge all combine to lead a juror to arrive at a more or less coherent interpretation of events, or gist representation of the case, which would typically support a decision about whether the defendant is liable for the plaintiff's injury. That is accomplished at the first stage. We expect that jurors essentially follow the first step of Pennington and Hastie's story model, organizing the evidence around causal interpretation to arrive at a liability determination.

In the second stage, which occurs during the trial or deliberation, the juror will also reach a categorical conclusion about whether damages are warranted. This categorical judgment (yes or no on damages) is followed by a third stage in which jurors make ordinal judgments relating to the injury's severity. We theorize that jurors code the specific injury the plaintiff has suffered as either severe or not severe, and consequently they determine whether the damage award that is deserved is low or high. Again, this prediction is based on research showing that once phenomena such as injuries are categorized, intuitions about

\footnotetext{
${ }^{44}$ Reyna et al., How Numeracy Influences Risk Comprehension, supra note 19.
} 
ordinal distinctions between low and high (but not specific numbers) are accessible in memory.

According to the theory, categorical and ordinal gist judgments are not based on adding up a list of facts, but on the interpretation of those facts, often as a coherent narrative, which supports a simple bottom-line intuition of yes or no to damages and, if yes, as low or high. If an injury cannot be ranked as either low or high, it will be relegated to a medium level of severity. In the final stage, the ordinal gist judgment about the injury's severity (low, medium, or high) will be mapped onto a number that corresponds to the gist of the award judgment. The juror will identify a number that is, to him or her, low, medium, or high, in order to match the perceived severity of injury.

Where do these numbers come from? We propose that jurors rely on symbolic numbers from everyday life that already have meaning to them as low or high numbers. One dollar is low; a million dollars is high, for example. In addition, the juror retrieves numbers from the case, such as medical costs, lost wages, and attorney ad damnum requests, numbers that the attorneys have convincingly portrayed as having a meaningful interpretation in the context of the case. The juror then selects a number that matches the ordinal (low, medium, high) gist of the injury. ${ }^{45}$

In sum, Figure 1 posits that jurors move through categorical (damages are warranted) and ordinal (the damages that are deserved are low, medium, or high) stages that are distinct from the process of attaching numbers that accord with this ordinal gist. We argue that jurors use qualitative meaning or the gist of the case to assess whether there is a fit with the gist of the proposed award. They then construct numbers that exemplify that gist of low versus high awards.

One might assume that a gist-based account is a better fit for the calculation of damages like pain and suffering or punitive damages, as opposed to economic damages that are assumed to be more well-defined and more closely linked to medical expenses, lost wages, property damage, and the like. However, both sorts of damages must be interpreted, even if there are precise dollar values attached to the economic damages. Thus, we anticipate that the model will help explain the full spectrum of damage award decisions.

The model does not yet include a full consideration of the group nature of jury damage awards, which we recognize as very important. However, the model has some implications for interactions among jurors with different ordinal gist interpretations of the case. First, juries consisting of members who view the gist as low and members who view the gist as high will center debate on the ordinal gist of the case. In contrast, juries of all low or all high gist members are more likely to debate the numbers, the size of the damage award

\footnotetext{
${ }^{45}$ Interestingly, David Ball, David Ball on Damages 3d ed. 238-42 (2011), proposes that attorneys employ a "scales" approach to help jurors map the severity of the injury onto dollar values. "The method you will now teach in closing helps jurors arrive at a figure; it also arms your favorable jurors with a concrete way to fight for the amount they want to allow." Id. at 238. He recommends that attorneys explain that the value of each noneconomic harm is based on how bad the injury is, how long the plaintiff is likely to experience pain, and how much it prevents the plaintiff from engaging in regular activities. "Where on the scale of disability does each harm lie? A disability can interfere with functioning anywhere from hardly at all up through total incapacity.... let's go up the scale another step to 'high'.... In a case like that, I would have to ask you for a verdict of a great deal of money, in the same proportion as the pain." Id. at. 239.
} 
that best corresponds to their shared gist of the case. Therefore, characterizing jurors according to their gist interpretations of a case will allow researchers to separate effects of mental representations of a case from difficulties in constructing appropriate numbers. Finally, juries composed of medium and low gist members (or medium and high gist members) will be unduly influenced by low or high gist members, respectively, even when they are fewer in number than medium jurors. Jurors who view damages as "medium" are less likely to influence the debate because they lack a clear, bottom-line interpretation of the case; research has shown that intermediate categories such as "medium" are used as hedges for unsure decisionmakers. ${ }^{46}$

Overall, this approach emphasizes the juror deliberation process as a search for a construal of the case that captures its essential bottom line. The approach also suggests that particular constellations of jurors with different construals or gist representations will interact in predictable ways, debating either the gist or the numbers, with disproportionate influence favoring jurors with low or high interpretations rather than wishy-washy "medium" jurors. Of course, jurors might also make compromises to reach a decision, adjusting awards to accommodate other views.

This framework implies that number construction-the process of selecting numbers to convey the gist of an injury-has its own complexities, distinct from construing the gist of the injury. An interesting question is whether people have a sense of what constitute "low" and "high" numbers (in our context, dollar awards) before confronting the particular situation or case at hand. Extensive work on numeracy has considered people's general ability to understand and use numbers. ${ }^{47}$ However, much of that work has emphasized rote computation.

We think that a better way to consider numeracy, especially as it is applied in the jury damage award setting, is as a contextual ability rather than a general one. Consider the statement that 1,000 bees have been counted in Ithaca, New York. If one is not an expert on bee populations in a town of this size and in this geographic location, it is difficult to know whether 1,000 bees is a large and newsworthy number or whether it represents a declining bee colony and thus cause for concern. The juror deciding on damages is often in a similar position, not knowing whether dollar amounts are appropriately low or high.

However, if the decisionmaker has experience in the relevant context-for example, a juror who works in the insurance industry, a lawyer with similarly injured clients, or a judge who presides over multiple personal injury cases—the decisionmaker might well have a numerical interpretation of "low" and "high" dollar values that can be marshaled in considering the present valuation of a plaintiff's injury. In this view, familiarity with the context of awards is an asset rather than a source of bias. (Of course, this type of comparative information is withheld from jurors deciding individual cases.) If such familiarity and experience are lacking, the decisionmaker will rely on what is provided in case facts or attorney arguments, or otherwise accessible and culturally available sources, that best

\footnotetext{
${ }^{46}$ Reyna \& Lloyd, supra note 40.

${ }^{47}$ Reyna \& Brainerd, Numeracy, Ratio Bias, and Denominator Neglect, supra note 18.
} 
reflect meaning or gist. For example, figures such as a billion dollars are widely perceived to represent "a lot of" money, whereas awards of one dollar are perceived as "nil." A year's profits, a day's sales, and other meaningful numbers can be used to provide a framework for constructing magnitudes of awards. More generally, meaningful numbers would be expected to be disproportionately influential in the minds of jurors as they attempt to match the award amounts to gist-based judgments of severity of damages.

\section{A. Similarities and Differences Between Our Model and the Story Model}

Our model builds on the story model of juror decision making developed by Nancy Pennington and Reid Hastie, and makes new predictions. ${ }^{48}$ Results supporting the story model's account of legal decision making, along with similar results from psycholinguistics, were part of the impetus for fuzzy-trace theory that we draw on in our gist-based model of damage award judgment. For example, Pennington and Hastie showed that mock jurors later recognized more case information consistent with their verdict than evidence inconsistent with it, and erroneously recognized verdict-consistent story elements that were never presented, a classic false memory effect. ${ }^{49}$ Although false-memory results were once taken to be evidence that memory is wholly reconstructive, many studies have shown that memory for details of information, verbatim memory, is independent of memory for meaning, or gist memory. By distinguishing between two kinds of memory, fuzzy-trace theory is able to predict both the meaning-based findings of the story model and discrepant findings regarding immediate memory for specific items of information.

The story model highlights the central meanings that jurors construct on the basis of the case facts, character of the parties, and contextual factors. In the gist-based model we propose, gist constitutes the core or central meaning of a story. The meaning of the story includes the categorical and ordinal gist, and therefore should influence the magnitude of the award ${ }^{50}$ The meaning of the story that the juror constructs may imply that a specific dollar value is highly significant-perhaps, for example, the dollar amount that the defendant gained as a result of the action that injured the plaintiff. Giving meaning to numbers is likely to encourage acceptance of such numbers when they resonate with the story the juror has constructed.

\footnotetext{
${ }^{48}$ Nancy Pennington \& Reid Hastie, A Cognitive Theory of Juror Decision Making: The Story Model, 13 Cardozo L. Rev. 519 (1991); Reid Hastie, What's the Story? Explanations and Narratives in Civil Jury Decisions, in Civil Juries and Civil Justice 23 (Brian H. Bornstein, Richard L. Wiener, Robert Schopp \& Steven L. Willborn eds., 2008).

${ }^{49}$ Nancy Pennington \& Reid Hastie, Explanation-Based Decision Making: Effects of Memory Structure on Judgment, 14 J. Experimental Psychol.: Learning, Memory \& Cognition 521 (1988). False memories were assumed to reflect reconstruction based on meaning (sometimes called "schematic memory"). See also Nancy Pennington \& Reid Hastie, Explaining the Evidence: Tests of the Story Model for Juror Decision Making, 62 J. Personality \& Soc. Psychol. 189 (1992). Although recent approaches to judgment and decision making stress Cartesian dual processes of rationality versus emotion, the dual processes of verbatim and gist processing resemble those of gestalt psychology, similarly distinguishing reasoning by rote and reasoning based on understanding. See Charles J. Brainerd \& Valerie F. Reyna, The Science of False Memory (2005).
}

${ }^{50}$ Valerie F. Reyna \& Barbara Kiernan, The Development of Gist Versus Verbatim Memory in Sentence Recognition: Effects of Lexical Familiarity, Semantic Content, Encoding Instruction, and Retention Interval, 30 Developmental Psychol. 178 (1994). 
However, it is important to distinguish what the gist-based model includes that is not included in the story model. The story model does not differentiate between gist and verbatim representations, even though the memory literature provides ample evidence that people distinguish between gist and verbatim representations and tend to rely more on gist than on verbatim representations in decision making. ${ }^{51}$ In addition, the story model does not assume that categorical and ordinal representations are constructed as a result of integrating the information about a case, only that jurors in later stages will develop representations of the verdict alternatives.

\section{Assessing the Validity of the Gist-Based Model with Jury AwARD DATa}

Our model hypothesizes that jurors make categorical and ordinal gist determinations, and then search for dollar award amounts that fit the gist judgments. Although key components of the general gist-based model have been tested in memory and decision-making research, carefully controlled experiments are needed to test the applicability of the model for jury damage award decision making. A test might measure participants' gist representations across a number of cases, as well as their gist of corresponding numbers in context (what corresponds to low, medium, and high dollar values in particular contexts). Both these measures should predict actual award determinations. Because jurors are assumed to have ordinal-level representations, we predict that awards will be ordinally coherent, but absolute award amounts should vary across contexts because what is perceived as low or high is inherently relative.

Although we have not yet done those studies, so we do not have a definitive test of our model, in this section we draw on research studies of jury awards to assess whether the observed patterns in these data are consistent with the model and its predictions. We do so mindful of Hastie's point that once one moves into the messy environment of real-world decision making, it can be challenging to assess the psychological underpinnings of observed phenomena. ${ }^{52}$

The model makes several specific predictions. First, jurors will search for meaningful numbers to give effect to their gist judgments. In addition, we should see patterning and scalloping around round numbers, which are easier to map onto gist judgments. Second, because of the ordinal nature of jurors' injury judgments and the damage awards that differently-injured plaintiffs deserve, we expect to observe ordinal regularities in jury awards. Third, even though ordinal regularities in jury awards should be present, judges' awards for similar injuries across cases should be less variable than juries' awards for similar injuries across cases. Judges as expert decisionmakers are more apt to make simple

\footnotetext{
${ }^{51}$ Brainerd \& Reyna, supra note 49; Herbert H. Clark \& Eve V. Clark, Psychology and Language: An Introduction to Psycholinguistics (1977); David A. Gallo, Associative Illusions of Memory (2006); Walter Kintsch, The Representation of Meaning in Memory (1974).
}

${ }^{52}$ Reid Hastie, The Challenge to Produce Useful "Legal Numbers," J. Empirical Legal Stud. (this issue). 
gist-based judgments, and to take advantage of comparative information about other similar cases, information that is withheld from juries. Finally, because gist is relative, and dollar amounts are interpreted relative to other quantities to give them meaning, anchor figures will influence jury awards. Anchors for juries' total damage awards might include economic damages, attorneys' ad damnum requests, and caps on damage awards. All four of these predictions find some support in the research on jury damage awards.

\section{A. Meaningful Numbers and Round Numbers}

The gist model predicts that jurors search for numbers that are meaningful to them and reflect the case's gist. Therefore, we are likely to observe patterns in the specific dollar figures of damage awards. Gist is easier to map onto round numbers because round numbers are not exact. Therefore, we expect to see numbers that are rounded off, particularly for noneconomic and punitive damages. ${ }^{53}$ Of course, any particular round number could be a precise number. However, if numbers are processed as continuous quantities rather than as categories, there should be no discontinuities or bumps in their perceived magnitudes. ${ }^{54}$ Instead, our model predicts that we should observe "scalloping" or "bumps" (i.e., certain numbers observed more frequently than adjacent numbers) at round numbers, and at numbers that signal category boundaries. These category boundaries might include distinctions between zero and any quantity, between certainty and uncertainty, and similar qualitative shifts.

New work shows that people have strong preferences for round numbers, consistent with the gist model. For example, a recent analysis of a large-scale digital scan of books showed a strong pattern in number frequency, which revealed an "extraordinary human fondness for round numbers.... Dollar amounts are even more dramatically biased in favor of well-rounded numbers." ${ }^{55}$

Data from the 2005 Civil Justice Survey of State Courts allow us to explore the extent to which national data about jury damage awards are consistent with predictions derived from the gist-based model we propose. The Civil Justice Survey is a joint project of the National Center for State Courts and the Bureau of Justice Statistics. The project sampled state courts of general jurisdiction in selected U.S. counties, and recorded information about tort, contract, and property cases decided in these courts during the calendar year 2005, including award information. ${ }^{56}$ The data set permits us to examine the relative

\footnotetext{
${ }^{53}$ Lacetera et al., supra note 21, at 1 (analyzing over 22 million wholesale used-car transactions, and finding "substantial evidence of . . . left-digit bias; there are large and discontinuous drops in sale prices at 10,000-mile thresholds in odometer mileage, along with smaller drops at 1,000-mile thresholds").
}

\footnotetext{
${ }^{54}$ Numbers are processed as both verbatim, continuous quantities and as fuzzy gist categories simultaneously, according to fuzzy-trace theory. Reyna \& Brainerd, Numeracy, Ratio Bias, and Denominator Neglect, supra note 18.
}

\footnotetext{
${ }^{55}$ Brian Hayes, Bit Lit, 99 Am. Sci. 190, 193 (2011) (showing relatively high frequency of round numbers in material scanned by Google Books).
}

${ }^{56}$ U.S. Dep't of Justice, Civil Justice Survey of State Courts, 2005 (Study No. 23862, 2005) [hereinafter Civil Justice Survey of State Courts, 2005]; Lynn Langton \& Thomas H. Cohen, Civil Bench and Jury Trials in State Courts, 2005 
frequency of round-number damage awards, as well as the relationship between different components of jury damages.

Figure 2 confirms the expectation, based on the cited work documenting roundnumber preferences, that jury awards are highly likely to end in round numbers. Analyzing the pattern of awards in the 2005 Civil Justice Survey, we find that a substantial proportion of damage awards end in zero.

Figure 2 shows some intriguing differences across damage award types. The first set of columns shows the general category of compensatory damages awarded to the plaintiff in judge trials and jury trials. The compensatory damage award variable includes awards of two types. Some states require only a general compensatory damage award figure that combines compensation for both economic and noneconomic damages. In other states, the award is given in separate amounts for economic damages and noneconomic damages. Coders summed these two amounts to arrive at an overall compensatory damage award for those cases. Both types of award, then, are included in the compensatory damages columns.

Figure 2: Proportion of damage awards ending in zero, by decisionmaker and damage award type.

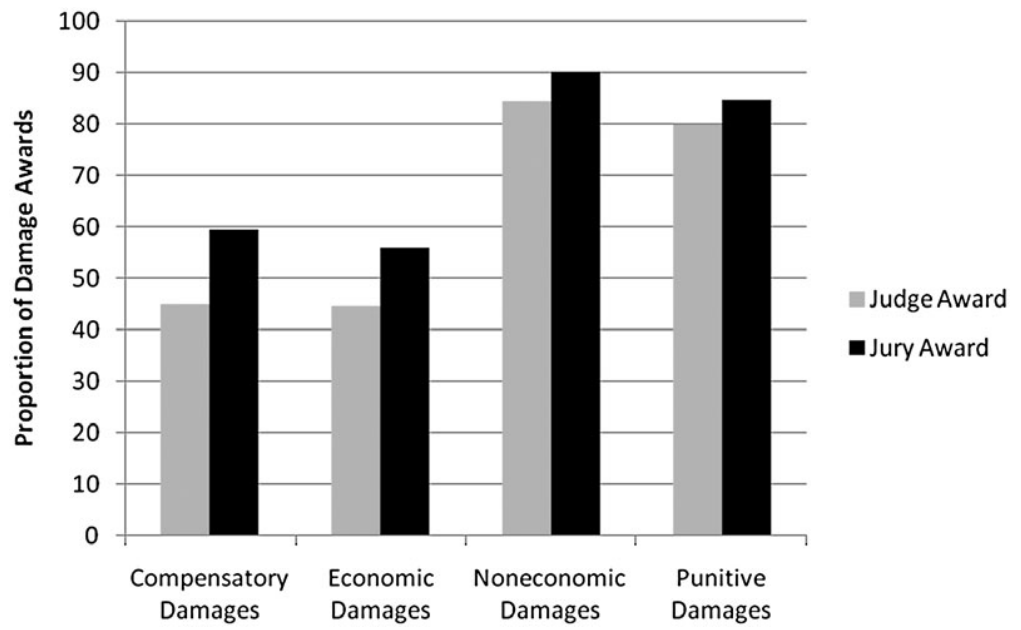

NoтE: Analyses are based on unweighted cases with overall plaintiff winners and nonzero positive awards. The initial awards before any adjustments are made are employed in the analyses. Number of cases included in the analyses: 4,452 for compensatory damages (which includes both economic and noneconomic damages); 3,745 for economic damages alone; 1,154 for noneconomic damages alone; and 188 for punitive damages. Awards were rounded to the nearest dollar by the original coders. Data from U.S. Department of Justice, Civil Justice Survey of State Courts, 2005 (Study No. 23862, 2005).

(Bureau of Justice Statistics Special Report 2009), available at <http://bjs.ojp.usdoj.gov/content/pub/pdf/ cbjtsc05.pdf> (describing major results of Civil Justice Survey). The analyses are conducted with unweighted cases with overall plaintiff winners and nonzero positive dollar awards. Analyses employed the initial awards reached by the trial judge or the jury before any adjustments were made to reflect the plaintiff's fault, awards to the defendant on cross-claims, caps, agreement between the parties, or other reasons. 
Overall, a little over half the compensatory damage awards end in zero. When we consider the subset of cases in which it is possible to view separately the economic and noneconomic components, we observe that noneconomic awards are substantially more apt to end in zero (90 percent) than awards for economic damages (52 percent). Like noneconomic awards, punitive damage awards are also highly likely to end in zero (84 percent overall).

Juries are more likely than judges to give awards that end in zero. The differences between judges and juries in the likelihood of awards ending in zero are statistically significant for both general compensatory awards and economic damage awards. ${ }^{57}$ Juries are slightly more apt than judges to arrive at awards that end in zero in the other two damage award categories, but the differences do not reach traditional levels of statistical significance.

Another factor in the likelihood of zero-ending awards is the award size. In compensatory and economic damage awards, the proportion of round-number awards increases as the amount of the award goes up. ${ }^{58}$ See Figure 3. For compensatory damage awards, the round-number awards are comparable in frequency until the awards reach 1 million dollars or more, when they jump significantly. For economic damage awards, the round-number

Figure 3: Proportion of damage awards ending in zero, by type and amount of damages.

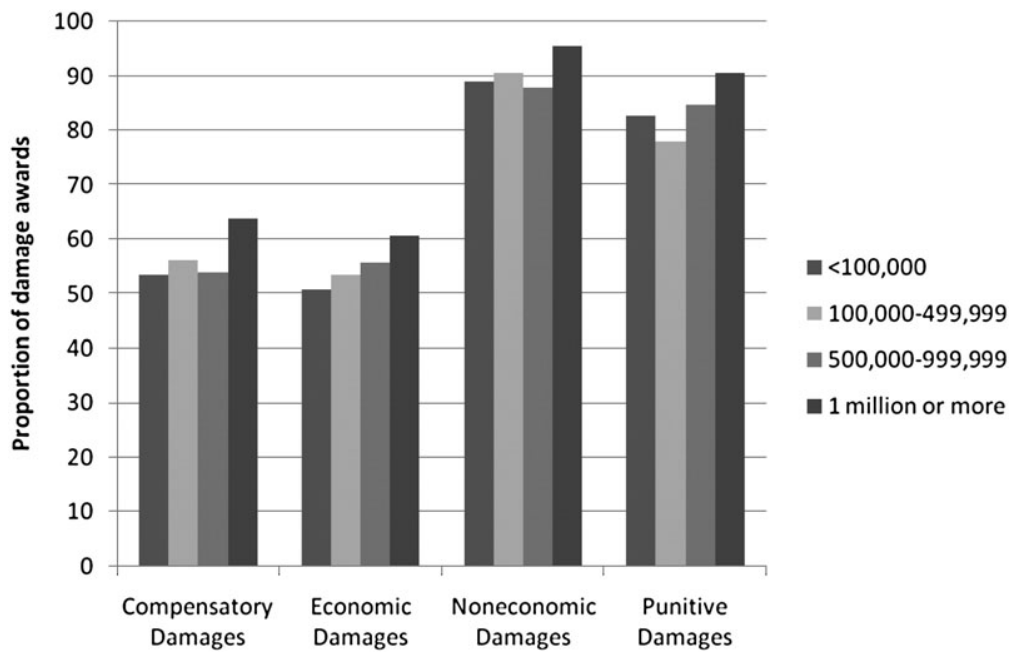

NotE: Analyses are based on unweighted cases with overall plaintiff winners and nonzero positive awards. The initial awards before any adjustments are made are employed in the analyses. Number of cases included in the analyses: 4,452 for compensatory damages (which includes both economic and noneconomic damages); 3,745 for economic damages alone; 1,154 for noneconomic damages alone; and 188 for punitive damages. Awards were rounded to the nearest dollar by the original coders. Data from U.S. Department of Justice, Civil Justice Survey of State Courts, 2005 (Study No. 23862, 2005).

\footnotetext{
${ }^{57}$ For compensatory damages, $\chi^{2}(1 d f)=84.93, p=0.000$; for economic damages, $\chi^{2}(1 d f)=43.73, p<0.001$.

${ }^{58}$ For compensatory damages, $\chi^{2}(3 d f)=12.90, p=0.005$; for economic damages, $\chi^{2}(3 d f)=8.2, p=0.04$.
} 
awards show a stair-step linear trend as the category amount increases in value. Figure 3 shows that in both the other award categories, there is a visible increase in the highest award amount category ( 1 million dollars or more), but in neither case does the increase achieve statistical significance.

These patterns are compatible with the gist model, and its expectation that jurors will map gist onto round numbers. The finding that judges, too, show a strong preference for round numbers is intriguing but consistent with the idea that expert decisionmakers often rely on gist determinations in their judgments. Of course, the tendency to adopt roundnumber figures could also be driven by attorney requests, expert testimony about predicted damages, or other dollar amounts mentioned during the trial that were round rather than precise numbers. It is quite likely that lawyers and experts share the factfinders' preference for round numbers. Interestingly, recent research shows that precise numbers are considered to be lower than comparable round numbers. ${ }^{59}$ That suggests that there could be strategic advantages for attorneys who ask the jury to consider precise rather than roundnumber damage awards. ${ }^{60}$

\section{B. Other Meaningful Numbers}

In addition to the pattern we have documented with round numbers, we would also expect to see overrepresentation of what jurors perceive as significant and meaningful sums (e.g., $\$ 10,000$, or $\$ 50,000$, or $\$ 1$ million). Jury deliberations about damages should routinely invoke the meaning behind particular numbers. It should be possible to investigate whether there is consensus within communities about the meaning of particular amounts of money in target contexts (i.e., whether $\$ 100,000$ is considered a large amount of money in the context of permanent disability, intentional pollution, etc.). Depending on the context, a particular amount could convey low or high gist. For example, a person's age, wealth, and earning capacity all may figure into whether a particular amount is perceived as low or high.

We have located several case examples that jurors search out meaningful numbers, and offer a few illustrations here, starting with one dollar awards and ending at the high end with a $\$ 5$ billion award.

\section{One Dollar Awards}

First is the rare but not unheard of situation of one dollar awards. In the 2005 Civil Justice Survey, there are a handful of damage awards of one dollar out of thousands of trials. ${ }^{61}$ Figure 4 shows that there are two cases in which there was a moderate economic damage

\footnotetext{
${ }^{59}$ Manoj Thomas \& Vicki Morwitz, Heuristics in Numerical Cognition: Implications for Pricing, in Handbook of Pricing Research in Marketing 132 (Vithala Rau ed., 2009); Thomas et al., The Price Precision Effect, supra note 25.

${ }^{60}$ For a direct application of the price precision effect to damage award requests, see David Davis, Some Juror Rules for Determining Damages, 20 Jury Expert 24 (2008).

${ }^{61}$ Civil Justice Survey of State Courts, 2005, supra note 56.
} 
award but the jury awarded just one dollar in noneconomic damages to the plaintiff. Looking ahead, one can identify these two cases in Figure 4, presented in a later section of this article; they are the two outlier cases at the $\log 10$ value of 0 for the noneconomic award. Likewise, Figure 5 shows a modestly-sized compensatory damage award by a jury that was accompanied by a one dollar punitive damage award. In anyone's book, a one dollar award is "low." Although some of the one dollar awards might be attributable to a token payment or a convention that does not reflect the jury's evaluation of the minimal worth of the case, at least some appear to be driven by the jury's gist of the injury's value.

The gist behind the choice of a one dollar award is nicely illustrated by the case of Ward Churchill, a controversial University of Colorado professor of ethnic studies, who created a firestorm of protest when he called victims of the September 11 attack "little Eichmanns," after the notorious Nazi war criminal. ${ }^{62}$ He was subsequently fired on grounds of research misconduct, but he sued the university, claiming that they fired him not because of that misconduct but because of his September 11 remarks, which he argued were protected on academic freedom grounds. The Colorado jury found for Churchill, but awarded him just $\$ 1$ in damages. The president of the University of Colorado said that the jury's nominal award was "an indication of what they thought of the value of Ward Churchill's claim." ${ }^{63}$

In Hans's interview study with civil jurors, they regularly faced-with some perplexity-the challenge of awarding monetary compensation to a plaintiff's spouse for loss of consortium. ${ }^{64}$ Although some jurors did not grant legitimacy to the idea of compensating a spouse on these grounds, they expressed concern that they avoid insulting the spouse. Often, $\$ 5,000$ did the trick. ${ }^{65}$ As the authors write: "about half of the loss of consortium awards in our study cases were exactly $\$ 5,000$. We wondered why so many juries independently had come up with this particular figure.... Unless jurors were strongly hostile toward those seeking loss of consortium, they were reluctant to return a zero award. To the jurors this zero award represented an insult or a slap in the face to the spouses, who often had to testify about revealing aspects of their personal lives in public.... Juries appeared to be awarding symbolic small amounts to avoid offending plaintiffs." 66

\footnotetext{
${ }^{62}$ See discussion in Ivan Moreno, Jury: Churchill Wrongfully Terminated, Awarded \$1, cbs4denver.com, Apr. 2, 2009 $<$ http://cbs4denver.com/local/verdict.churchill.colorado.2.974641.html>. See also Peter Schmidt, Churchill Wins Lawsuit, But Only \$1 in Damages, Chron. of Higher Educ., Apr. 3, $2009<$ http://chronicle.com/article/ChruchillWins-Lawsuit-but/47157>; Peter Schmidt, Ward Churchill's \$1 Damage Award Said to Have Been Product of Jury Compromise, Chron. of Higher Educ., Apr. 3, $2009<$ http://chronicle.com/article/Ward-Chruchill-s-1Damage/42681>.
}

${ }^{63}$ Schmidt, Churchill Wins Lawsuit, But Only \$1 in Damages, supra note 62.

${ }^{64}$ Valerie P. Hans \& Michelle Hallerdin, Juror Skepticism Toward Plaintiffs: The Example of Loss of Consortium Claims. Paper presented at the meeting of the American Psychology-Law Society, San Diego, CA (Mar. 13, 1992).

${ }^{65}$ Id. at 8 .

${ }^{66} \mathrm{Id}$ 


\section{Meaning in Extremely Large Awards}

We believe that the gist model helps explain the specific dollar amounts in some extremely large jury awards, amounts that very often seem inexplicable and irrational to outside observers. ${ }^{67}$ In the well-known McDonald's coffee-spill case, the plaintiff's attorney in the case argued to the jury that it might want to punish McDonald's for one or two days' worth of coffee sales. He estimated that that amounted to about $\$ 1.35$ million per day. The jury concluded that an appropriate punishment was two days' worth of sales, hence the punitive damages award of $\$ 2.7$ million. $^{68}$

Also consider the $\$ 5$ billion punitive damage award against the Exxon Corporation in connection with the massive oil spill from the Exxon Valdez; the accident occurred when the captain was drunk and was away from the bridge. ${ }^{69}$ An in-depth journalistic account, including material based on interviews with the jurors, who described their deliberations over punitive damages, provides support that the $\$ 5$ billion figure for typical yearly worldwide profits for Exxon influenced the choice of punitive damage award..$^{70}$ The plaintiff's attorney O'Neill argued to the jury that Exxon should pay punitive damages of somewhere between $\$ 5$ and $\$ 20$ billion. He also displayed a chart with Exxon's revenues, net income, and net worth. Jurors deliberated, but could not agree on a figure. "After about 50 votes, the jury was closing in on the $\$ 5$ billion figure. ... [the majority] agreed to $\$ 5$ billion. That left Wilson, Dean and Provost. Wilson was the next to agree.... But Dean and Provost remained fixated on $\$ 3.51$ billion, Exxon's profits the year of the spill. Eventually, Dean decided that $\$ 5$ billion was 'the happy medium' and he joined the crowd. That left Provost. Driving home that night, Provost said she started thinking. Exxon's profits were \$3.51 billion the year of the spill, but typically the company posted $\$ 5$ billion in profits. Had the company not spent a couple billion cleaning up the spill, profits for 1989 would have been $\$ 5$ billion. That was good enough for Provost." Note that the final awarded amount did not approach what half the jurors had initially recommended, but settled instead on the highly symbolic amount of one year's usual profits.

\footnotetext{
${ }^{67}$ Sunstein et al., supra note 14 , at 3 , write with dismay about the California jury that awarded close to 5 billion dollars, reportedly based on an estimate of the yearly advertising budget of the negligent company. If it is the case that jurors relied on the annual advertising budget, we view this as another example of jurors searching in the case for meaningful numbers that accord with their gist of the magnitude of the deserved damages.
}

${ }^{68}$ Andrea Gerlin, How a Jury Decided that a Coffee Spill is Worth $\$ 2.9$ Million, Wall St. J., Sept. 1, 1994, at A1; Hans, Business on Trial, supra note 3, at 70-72.

\footnotetext{
${ }^{69}$ In re the Exxon Valdez, 270 F.3d 1215, 1238-39 (9th Cir. 2001). The Ninth Circuit's opinion concludes that the jury may have considered yearly Exxon profits as a meaningful benchmark: "This was a very bad oil spill. Captain Hazelwood's conduct, interpreting the evidence most strongly against him, was extremely reckless considering the difficulty and potential risk of his task, and Exxon was reckless to allow him to perform this task despite its knowledge that he was drinking again. The punitive damages amount, $\$ 5$ billion, is about one year's net profits for the entire world-wide operations of Exxon, and the jury may well have decided that for such egregious conduct the company responsible ought to have a year without profit."
}

${ }^{70}$ Natalie Phillips \& Staff, The $\$ 5$ Million Jury: For 18 Weeks, the Exxon Valdez Trial Jurors Listened, Argued, Laughed and Sometimes Even Dozed Off, Anchorage Daily News (AK), Jan. 22, 1995. 


\section{E. Ordinal Regularities in Jury Damage Awards}

To the extent that there is societal consensus about relative harms, and overlap in what people consider to be low, medium, and high amounts of money, we predict ordinal regularities in the awards reached by juries. That is, even though they decide different cases at different times, juries will compensate those who have minor injuries less than those who have major injuries. As described earlier, evidence confirms these ordinal regularities in actual jury awards. ${ }^{71}$ To provide a few additional examples, consistent with the idea that ordinal gist judgments characterize juror evaluations and juror damage award preferences, the research by Sunstein and colleagues on punitive damages found that "judgments of punitive intent and of dollar awards share the same core of moral outrage, and therefore produce the same ordering of cases." ${ }^{\prime 2}$ In another judgment domain, Hastie cites work on consumer pricing that reveals that once consumers are anchored on a figure, they are "meticulous in maintaining a single coherent ordering on prices across products." ${ }^{73}$ Eisenberg, Hans, and Wells combined award data from three different civil trial data sets, one that included a broad range of awards, and two others that focused specifically on high damage award cases. Analyzing the logged dollar values of punitive and compensatory awards from these three data sets combined, they found a predominantly linear relationship, supporting our expectation of an ordinal pattern. ${ }^{74}$ Similarly, Eisenberg and Heise analyzed the punitive-compensatory relationship in four Civil Justice Survey data sets and confirmed the positive association between the two types of awards. ${ }^{75}$

Data from the 2005 Civil Justice Survey of State Courts allow us to take a fresh look at the question of the relationship between the dollar values of noneconomic and economic damage awards reached by juries and, by way of contrast, the awards of judges as well. ${ }^{76}$ Analyzing the relationship between economic and noneconomic damage awards in the Civil Justice Survey data set, we expect to find, for both judges and juries, an ordinal relationship whereby the larger the economic damages, the larger the noneconomic damages. The relationship may be stronger for judges than for juries, if they place greater weight on the plaintiff's economic harm than juries do. Alternatively, if judges use

\footnotetext{
${ }^{71}$ Eisenberg et al., Real-World Coherence, supra note 28; Eisenberg, Hans \& Wells, supra note 29; Catherine M. Sharkey, Dissecting Damages: An Empirical Exploration of Sexual Harassment Awards, 3 J. Empirical Legal Stud. 1 (2006).

${ }^{72}$ David Schkade, Cass R. Sunstein \& Daniel Kahneman, Deliberating About Dollars: The Severity Shift, 100 Colum. L. Rev. 1139, 1152 (2000); see also Sunstein et al., supra note 14, at 48-49.

${ }^{73}$ Hastie, supra note 52 , at 12 .

${ }^{74}$ Eisenberg, Hans \& Wells, supra note 29. See also Theodore Eisenberg, Michael Heise, Nicole L. Waters \& Martin T. Wells, The Decision to Award Punitive Damages: An Empirical Study, 2 J. Legal Analysis 577, 608 (2010) [hereinafter Eisenberg et al., The Decision to Award Punitive Damages] (examining the relationship between compensatory and punitive damages in the 2005 data).
}

${ }^{75}$ Theodore Eisenberg \& Michael Heise, Judge-Jury Difference in Punitive Damages Awards: Who Listens to the Supreme Court? 2 J. Empirical Legal Stud. 325, 343 (2011).

${ }^{76}$ Civil Justice Survey of State Courts, 2005, supra note 56. 
information outside the individual case to arrive at noneconomic damage amounts, the relationship may be weaker.

Figure 4 displays the relationship between the logged economic and noneconomic damages for cases with overall plaintiff winners and nonzero positive dollar values on each type of damage award. Jury awards are represented by open circles; awards given by judges in bench trials are represented by stars.

In both judge and jury trials, the economic damage award reached by the decisionmaker is a significant predictor of the noneconomic damage award. Furthermore, one can observe predominantly linear relationships between the two types of awards, such that the larger the economic damage award decided by the judge or the jury, the larger the noneconomic damage award. The slope appears steeper for jury awards than for judge awards, although the interaction term between the economic damage award and the decisionmaker is only marginally significant $(p<0.09)$. That suggests that the amount of

Figure 4: The relationship between economic and noneconomic damage awards in bench and jury trials.

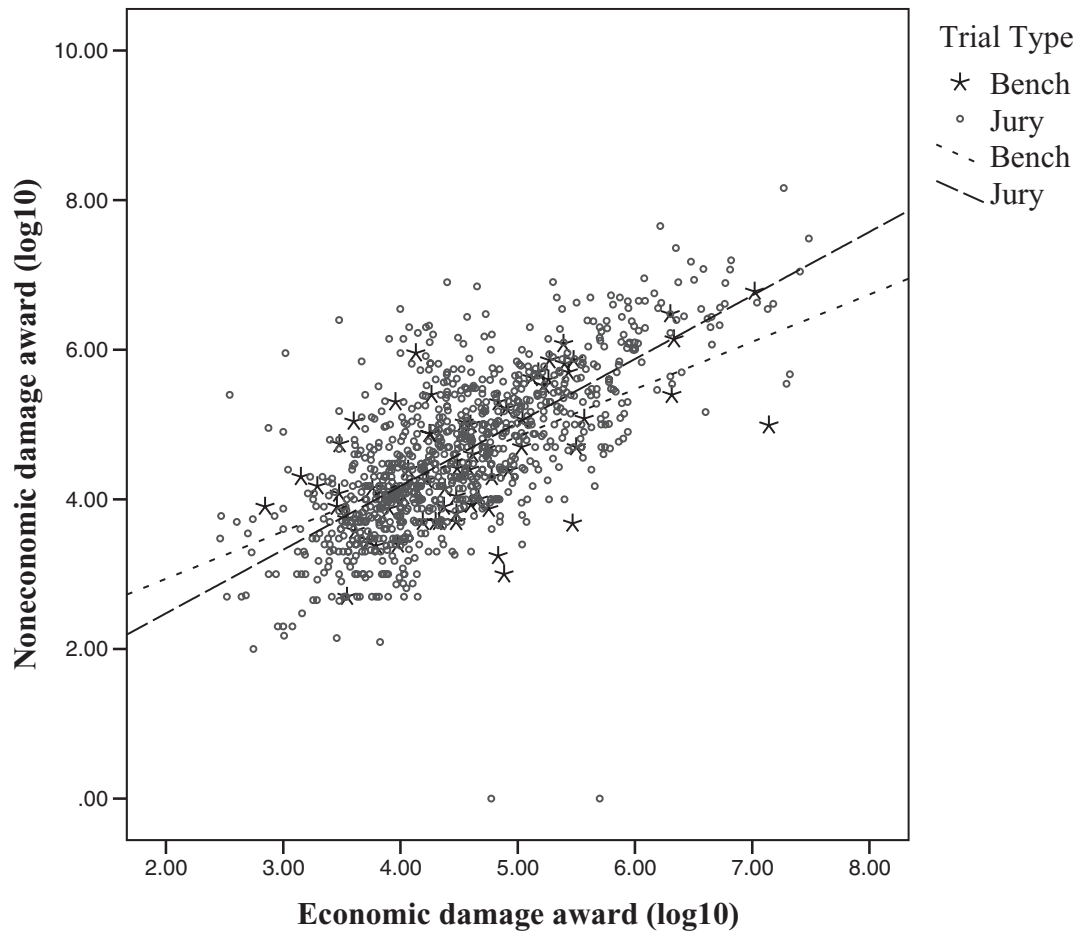

Note: Analyses are based on unweighted cases with overall plaintiff winners and nonzero positive dollar awards for each type. The initial awards before any adjustments are made are employed in the analyses. Awards were rounded to the nearest dollar by the original coders. Analyses included 921 jury awards and 64 bench awards. Bench $R^{2}$ (linear) $=0.375$; Jury $R^{2}$ (linear) $=0.493$. Data from U.S. Department of Justice, Civil Justice Survey of State Courts, 2005 (Study No. 23862, 2005). 
economic damage that a plaintiff experiences in a case serves as a slightly stronger determinant of the noneconomic damage award for juries as compared to judges.

Figure 5 shows a similar analysis of awards from the 2005 Civil Justice Survey, but this time for the relationship between the total compensatory awards (which combine both economic and noneconomic damages) and the punitive damage awards. The analysis is limited to those cases with overall plaintiff winners and nonzero positive dollar values for both compensatory and punitive damage awards. As before, jury awards are represented by open circles; awards given by judges in bench trials are represented by stars.

Again, the relationship between the two types of damage awards is generally similar for both judge and jury, reflecting a strong ordinal pattern in which low and high compensatory damage cases net low and high punitive damage awards, respectively. The slope is significantly $(p<0.05)$ steeper for jury awards than for judge awards. The degree to which the plaintiff requires compensatory damages in a case is a stronger determinant of a punitive damage award for juries than for judges. It is worthwhile noting that cases are not

Figure 5: The relationship between compensatory and punitive damage awards in bench and jury trials.

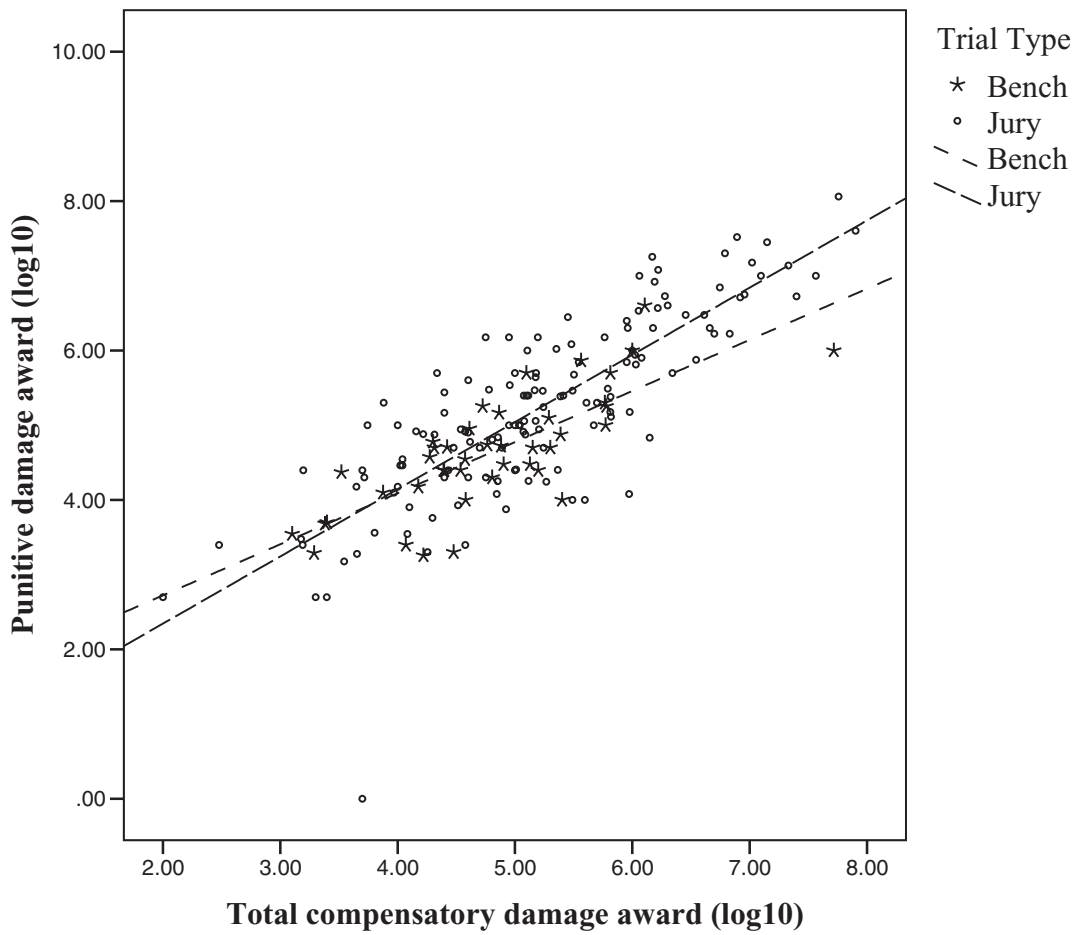

Note: Analyses are based on unweighted cases with overall plaintiff winners and nonzero positive dollar awards for each type. The initial awards before any adjustments are made are employed in the analyses. Awards were rounded to the nearest dollar by the original coders. Analyses included 138 jury awards and 42 bench awards. Bench $R^{2}$ (linear) =0.599; Jury $R^{2}$ (linear) $=0.664$. Data from U.S. Department of Justice, Civil Justice Survey of State Courts, 2005 (Study No. 23862, 2005). 
randomly assigned to judge and jury trials, and case routing as well as other differences between judges and juries might account for the slightly different patterns observed.

If we take the underlying compensatory damage awards as revealing the factfinder's ordinal rankings of harm done, and we do, then finding ordinal regularities such as the one observed for the compensatory-punitive damage relationship reinforces the model's presumption of the importance of ordinal ranking in jury damage award judgments even in punitive damages, which are thought to be erratic and inexplicable. ${ }^{77}$ In sum, our model predicts, and the available research on jury damage awards generally finds, that there are coherent ordinal patterns in award determinations.

\section{F. Jury Awards Should Vary More Than Judge Awards}

Even though ordinal regularities in jury awards are observed, the model predicts that jury damage awards will vary more than judge damage awards for the same types of injuries and cases. The reasons are twofold. Because judges are expert decisionmakers, we can predict that their judgments will be even more likely to be simple gist-based judgments. But more importantly, judicial awards will be less variable because their contextual experience offers them comparative information, and juries do not have this advantage. ${ }^{78}$ Indeed, it is possible that judges' reliance on contextual or comparative information explains the flatter slopes for judge awards in Figures 4 and 5 .

Analysis of damage awards in the 2005 Civil Justice Survey data set by other scholars confirms the expectation that jury awards in the aggregate are more variable than judge awards in the aggregate, consistent with the model's expectations. ${ }^{79}$ Greater variability in jury awards compared to judge awards in actual jury and judge decisions, of course, is not necessarily dispositive evidence for the model. Future research must independently assess the value of cases because different, and higher dollar value, cases are typically routed to juries. ${ }^{80}$ Thus, it is important to develop methods to tease apart, and adjust for, case differences in order to study decisionmaker differences.

\section{G. Anchors Should Affect Jury Decision Making}

Our model anticipates that anchors will influence jury damage award assessments. A number of psychological mechanisms are thought to produce anchoring, including confirmatory hypothesis testing, insufficient adjustment, and numeric priming. ${ }^{81}$ Fuzzy-trace

\footnotetext{
${ }^{77}$ See, for example, Sunstein et al., supra note 14, at 3 ("inexplicable") and 31 ("erratic").

${ }^{78}$ For a discussion of the fact-finding advantages of judges over juries, see Valerie P. Hans, Judges, Juries, and Scientific Evidence, 16 J.L. \& Pol'y 19 (2007).

${ }^{79}$ Eisenberg \& Heise, supra note 75, at 331 (showing, for 2005 data, higher means, medians, and standard deviations for juries' compensatory and punitive damage awards, compared to judges' awards).
}

${ }^{80}$ Id. See also Kevin M. Clermont, Litigation Realities Redux, 84 Notre Dame L. Rev. 1919 (2009).

${ }^{81}$ Nicholas Epley \& Thomas Gilovich, Anchoring Unbound, 20 J. Consumer Psychol. 20 (2010). 
theory anticipates that anchors will influence award amounts because gist is relative. Dollar amounts, just like probabilities and other quantities, are interpreted relative to other quantities to give them meaning. Furthermore, anchors presented during trial should have a stronger impact on jury assessments than on judge assessments because judges are apt to have contextual and comparative information about other cases that may counteract or outweigh the impact of anchors presented during trial.

The research literature on anchoring includes many successful demonstrations of the anchoring process using arbitrary or nonsense anchors, such as numbers from a roulette wheel spin or the last four digits of a Social Security or telephone number. Our gist-based model anticipates that people may be influenced by arbitrary anchors in information-poor environments. We assume that there is no number in the head that can be discovered through better measurement; therefore, other numbers, including anchors, provide needed context to flesh out damage awards that are perceived as low or high. However, in our model, there is a strong expectation that a meaningful anchor will be more persuasive than an arbitrary one, so long as it is consistent with the gist that jurors extract from the facts.

Evidence presented in a typical civil jury trial functions as a naturally occurring, and often meaningful, anchor. The amount of economic damage, whether it is provided quantitatively in dollars or qualitatively in magnitude estimates, serves as one important guidepost for jurors, as Figure 4 indicates. ${ }^{82}$ The strong connection between compensatory and punitive damages shown in Figure 5 is consistent with the possibility that compensatory damages serve as anchors for decisionmakers as they deliberate on the amount of punitive damages to award.

One type of anchor produced by attorneys as part of a persuasion effort is the attorney's ad damnum or request for a specific damage award figure. Experiments on attorney requests such as ad damnums show, consistent with our model's predictions, reliable effects of plaintiff and defense ad damnums. ${ }^{83}$ Variation in the way that figures are submitted to the jury can also change the resulting damage award. For example, McAuliff and Bornstein varied whether their study participants heard a lump-sum ad damnum or heard a per-diem amount request for an award to compensate the plaintiff for pain and suffering. ${ }^{84}$ Attorney requests for a lump sum of $\$ 175,000$ and an hourly rate of $\$ 10$ produced higher damage

\footnotetext{
${ }^{82}$ Other studies have also found links among injury severity, economic damages, and pain and suffering awards. See Randall Bovbjerg, Frank A. Sloan \& James F. Blumstein, Valuing Life and Limb in Tort: Scheduling "Pain and Suffering," 83 NW U.L. Rev. 908 (1989); Gregory B. Rodgers, Estimating Jury Compensation for Pain and Suffering in Product Liability Cases Involving Nonfatal Personal Injury, 6 J. Forensic Econ. 251 (1993) (using jury award data from Jury Verdict Research, Inc., and finding that pain and suffering compensation are related to injury severity and economic losses); Vidmar \& Hans, supra note 28, at 281-302.
}

${ }^{83}$ Shari Seidman Diamond, Mary R. Rose, Beth Murphy \& John Meixner, Anchors and Set Asides on Real Juries, J. Empirical Legal Stud. (this issue); Greene \& Bornstein, Determining Damages, supra note 1, at 150-59.

${ }^{84}$ Bradley D. McAuliff \& Brian H. Bornstein, All Anchors Are Not Created Equal: The Effects of Per Diem Versus Lump Sum Requests on Pain and Suffering Awards, 34 Law \& Hum. Behav. 164 (2010). 
awards than $\$ 240$ per day or $\$ 7,300$ per month, even though all the per-diem payments approximated the lump-sum payment. ${ }^{85}$

Regulations of ad damnums vary across jurisdictions. Some states, for example, do not permit an attorney to suggest total dollar figures or per-diem amounts to the jury. Assuming that attorney recommendations are related to the relative severity of their cases, we predict that if attorney recommendations on damage award totals are allowed, that will reduce the variance compared to sets of cases without attorney recommendations, all else equal. ${ }^{86}$ The effect of ad damnums could be challenging to tease apart in the real world because attorney requests are linked to the value of their cases. Thus it would be difficult to determine whether jury judgments in line with ad damnums are driven by the ad damnums themselves, above and beyond the value of the cases. Furthermore, there could be other differences in the caseloads of jurisdictions that do or do not allow attorneys to offer ad damnums. It is also possible that attorney recommendations bear little relationship to the value of their cases, or that plaintiff recommendations are substantially higher than typical awards, in which case ad damnums might have no effect or might even exacerbate the unpredictability of jury awards. However, comparing cases with comparable economic or other independently assessed valuations in jurisdictions with and without ad damnums offers an opportunity to estimate effects of ad damnum recommendations as anchors.

Caps or absolute limits on damage awards may also operate as anchors, if they become known to the jury. If a cap becomes known to the jury, it has the effect of changing the dollar scale from an unbounded to a bounded scale, with a known low and high point. In theory, this should rationalize jury awards within the jurisdiction. In essence, jurors are provided with state-sanctioned "low" and "high" values, and the jurors need only map their own ordinal gist determinations onto the bounded scale, a much simpler cognitive task than generating one's own low and high values and then constructing numbers that fit. The gist model expects that, compared to jurisdictions without caps, caps jurisdictions should be characterized by stronger relationships between injury severity and the dollar value of the awards.

Research on the effects of caps shows some influence on damage awards, but with a paradoxical twist. In experiments testing the impact of award caps, when the dollar amount of a damages cap becomes known and operates (presumably) as a psychological anchor, it appears to hoist up what otherwise would have been relatively low awards in no caps conditions. ${ }^{87}$ Other work indicates that when noneconomic damages are limited by a cap,

\footnotetext{
${ }^{85}$ Id. at $169-70$.

${ }^{86}$ McAuliff \& Bornstein, supra note 84, at 170 , however, found that the award amount and the variability were both lower for the control condition in which no ad damnum was requested. In general, as award amounts increase, variability also increases, making it difficult to test our variability prediction.

${ }^{87}$ Avraham \& Bustos, supra note 9 (undertaking an economic analysis that finds that under a caps regime, although severely injured plaintiffs will recover less, plaintiffs with low injuries may recover more, compared to similarly injured plaintiffs in noncaps states).
} 
economic damages rise. ${ }^{88}$ This malleability of numerical judgments relative to different comparative amounts is consistent with predictions of our model and fuzzy-trace theory.

\section{Conclusion}

We believe the gist-based model makes a contribution in emphasizing, as other accounts of jury damage award decision making generally do not, the central importance of the meaning of numbers. The story model also privileges meaning in its narrative account, but in a subtly different way. The story model emphasizes the narrative itself, the way facts hang together in a coherent account. The gist-based approach stresses the narrative too, but goes further to posit that jurors derive categorical and ordinal judgments from the meaning or gist of the narrative. It also claims that jurors come to associate particular dollar amounts with meaning in the context of the trial. Exact numbers have little significance, even to the highly numerate, until the numbers can be interpreted relative to specific content and contexts. Thus, anchors have an effect on numerical interpretation, especially when judgments are unfamiliar, as they provide a context in which numbers can be interpreted as low or high, relative to the anchor.

One advantage of the gist-based model of jury damage awards is that in future work we should be able to use research on the significance of cues and framing to predict when verbatim versus gist approaches will dominate juror decision making about damages. In particular, does requiring jurors to answer interrogatories and reach special verdicts affect their tendency to employ verbatim rather than gist thinking? The case examples suggest that attorneys' arguments for awards can be successful when they propose numbers that accord with jurors' gist of the injury. It would be valuable to study this in a controlled experiment.

The gist-based account is, we think, a more positive take on the jurors' approach to damage decisions. The gist that we say drives jurors as they consider damages is not presumed to be naïve and immature reasoning. Indeed, we observe and can now explain some regularities and patterns to jury damage awards, whereas before it looked to some observers as though jurors were erratically grasping at numbers out of thin air.

The impact of anchors is well-documented in the experimental literature. In the courtroom, there is an abundance of anchoring information in actual cases that reflects the value of the case. Attorneys provide anchors by offering ad damnums in jurisdictions that permit them, or by calling fact witnesses and expert witnesses who estimate monetary losses. ${ }^{89}$ We have noted above the strong patterns we find with economic damages, noneconomic damages, and punitive damages. The agreement across these types of damages is generally ordinal, not absolute, as would be predicted by our model.

\footnotetext{
${ }^{88}$ Sharkey, Crossing the Punitive-Compensatory Divide, supra note 9.

${ }^{89}$ Diamond et al., supra note 83 .
} 
There are also built-in controls and protection against erratic awards. The jury has the gist. Attorneys and judges have comparative information about similar cases. Attorneys can (and do) appeal and judges can (and do) review and modify jury awards. Substantial research shows that the final amounts that defendants pay are a fraction of what is awarded. ${ }^{90}$ So, the final jury awards reflect the combined perspectives of juror gist-based reasoning about a case as well as legal actors' broad contextual knowledge. Because jurors are not constrained in their initial categorical and ordinal judgments by comparative information, this also allows for changes over time in the way the U.S. public evaluates the meaning and significance of injury to be incorporated into damage awards. ${ }^{91}$

\footnotetext{
${ }^{90}$ David A. Hyman, Bernard Black, Kathryn Zeiler, Charles Silver \& William M. Sage, Do Defendants Pay What Juries Award?: Post-Verdict Haircuts in Texas Medical Malpractice Cases, 1988-2003, 4 J. Empirical Legal Stud. 3 (2007). Federal law permits judges to reduce (remittitur), but not to increase (additur) jury damage awards. Richard H. Field, Benjamin Kaplan \& Kevin M. Clermont, Civil Procedure: Materials for a Basic Course 9th ed. 1417-27 (2007). States vary in the extent to which they permit the judge both to increase and decrease jury damage awards. Benjamin V. Madison, III, Civil Procedure for All States: A Context and Practice Casebook 278-79 (2010).
}

${ }^{91}$ Valerie P. Hans, Juries as Conduits for Culture, in Fault Lines: Tort Law and Cultural Practice 80 (D. M. Engel \& M. McCann eds., 2009). 